\section{Adaptação climática na saúde e bioética}

\section{Alcântara, Ricardo Wagner de Souza}

Universidade de Brasília (UnB) - Faculdade de Ciências da Saúde - Cátedra UNESCO de Bioética - Programa de Pósgraduação em Bioética. e-mail: ricardoalcantara@hotmail.com

PALAVRAS-CHAVE: Bioética - Adaptação climática Saúde - Abordagem das Capacidades.

Introdução: A relação entre o aumento da temperatura do planeta e diminuição nos níveis de saúde representa a face humana mais dramática das mudanças climáticas. As regiões pobres do planeta e as populações vulneráveis sofrerão mais, em que pese sua menor contribuição para a mudança climática antropogênica, cujos efeitos prejudicam as condições gerais de desenvolvimento humano, dificultando ou impossibilitando, direta ou indiretamente, a capacidade dos indivíduos serem saudáveis. As populações vulneráveis estarão mais sujeitos a eventos extremos, à escassez de água e alimentos e à proliferação de vetores de doenças. Avanços inegáveis alcançados na saúde pública no século passado podem ser revertidos drasticamente em decorrência do fenômeno. $\mathrm{O}$ esforço de adaptação às novas condições climáticas é urgente no campo da saúde. O escopo deste estudo é buscar enfoque bioético da adaptação climática em saúde, que é evidente foco de conflitos de natureza ética, lançando mão do referencial da abordagem das capacidades. Método: Estudo baseado em revisão bibliográfica da abordagem das capacidades, destacando a ideia de saúde como meta-capacidade de Shidar Venkatapuram e sua aptidão para o enfoque bioético da adaptação climática na saúde. As críticas a este paradigma existentes em bases científicas (Pubmed, Medline, Scielo e Google Scholar) também foram cotejadas, bem como a perspectiva de Breena Holland, que toma a sustentabilidade ecológica também como meta-capacidade. Resultados: Dentre os vários referenciais teóricos que poderiam ser utilizados para a análise da adaptação climática em saúde, a abordagem das capacidades - em especial os enfoques que aceitam a ideia de saúde e sustentabilidade ecológica como meta-capacidades - transparece como referencial teórico promissor para a abordagem bioética da adaptação climática em saúde e para a construção de diretrizes éticas para os conflitos morais na adaptação climática. Conclusões: A construção de soluções pacíficas para conflitos morais inerentes à adaptação climática em saúde, em especial em três cruciais dimensões éticas - a vulnerabilidade dos atingidos pela mudança climática, a distribuição de recursos escassos e a deliberação e transparência nas decisões políticas - pode ser muito enriquecida com o enfoque bioético a partir da abordagem das capacidades.

\section{REFERÊNCIAS}

[1] IPCC. IPCC 2014. Climate Change 2014: Synthesis Report. Contribution of Working Groups I, II and III to the Fifth Assessment Report of the Intergovernmental Panel on Climate Change. 2014. 2-26 p.

[2] Nussbaum, Martha C. Fronteiras da Justiça: Deficiência, Nacionalidade, Pertencimento à espécie. Trad. de Susana de Castro. São Paulo: Editora WMF Martins Fontes, 2013.

[3] Venkatapuram, Sridhar. Health Justice: An Argument from the Capabilities Approach. Polity Press, Cambridge, 2011.

[4] Holland, Breena. Justice and the Environment in Nussbaum's "Capabilities Approach": Why Sustainable Ecological Capacity is a Meta-Capability. Political Research Quarterly. Vol. 61, No. 2, June 2008, 319-332.

[5] Robeyns, Ingrid. The Capability Approach: a Theoretical Survey. Journal of Human Development, Vol. 6, No. 1, March 2005. 